\title{
ICT: Health's best friend and worst enemy?
}

\author{
Egon L. van den Broek \\ Department of Information and Computing Sciences, Utrecht University, PO Box 80.089, 3508 TB Utrecht, The Netherlands \\ http://www. human-centeredcomputing.com/ \\ vandenbroek@acm.org
}

Keywords: ICT, Health Problems, Stress, Black Plague, Affective Computing, Emotion, Personality, Coping

\begin{abstract}
I propose a paradigm shift for health care, as there is an urgent need for i) continuous (semi-)automatic medical checkups, ii) cost reduction, and iii) cure for the 21 st century black plague (i.e., stress-related diseases) are very much needed. To realize this ICT's Paradox has to be solved. On the one hand, ICT can cause i) musculoskeletal problems, ii) vision problems, iii) headache, iv) obesity, v) stress disorders (e.g., burn out), vi) metabolic issues, vii) addiction (e.g., to games, social media, and Internet), viii) sleeping problems, ix) social isolation, and $\mathrm{x}$ ) an unrealistic world view. On the other hand, ICT claims to provide these problems' solutions. Consequently, health informatics needs to adopt a holistic approach, improve its fragile theoretical frameworks, and handle the incredible variance we all show. As a remedy, I propose to take up the challenge to next-generation models of personality, as they are a crucial determinant in people's stress coping style.
\end{abstract}

Your worst enemy

Becomes your best friend,

once he's underground.

- Euripides -

\section{INTRODUCTION}

Our health care system is not neither functioning effectively nor effectively. "Many of the changes intended to improve or reform health care are resulting in increased costs, increased work, and little (if any) improvement in health." (Bartol, 2016) For example, the much discussed electronic health records were meant to improving care; but, show to be complicated and inefficient. Medical doctors, nurse practitioners as well as patients are forced to check more boxes, use more technology, and produce more data, without health care improving or costs declining (Bartol, 2016; Stylianou and Talias, 2017).

Health care does not need to reform or transform, it needs to be recreated from the bottom-up, it needs a paradigm shift! "Attempts at reforming and transforming health care have been like repairing or fixing up a 50-year-old car, adding newer equipment and modern technology to try to make it better. The problem is that we do not consider if the original vehicle is really what is needed today." (Bartol, 2016) "Health care systems around the world are both highly institutionalized and highly professionalized." (Ferlie et al., 2016). Their processes are directed to patients and their symptoms, using procedures and medication. Hereby, the focus on on treating the ill, ignoring the healthy. So, resources are spend on health care's high spenders, where we ignore the healthy.

There are, at least, three reasons to support this call for this paradigm shift:

i) Continuous (semi-)automatic medical checkups (Jarvis, 2016) and support for healthy living should become part of common health care;

ii) Extent healthy people's health could reduce health care costs significantly; and

iii) Stress-related diseases are rapidly becoming the dominant class of illness.

Next-generation medical check-ups could benefit from the many types of health care data (Stylianou and Talias, 2017), including (Fang et al., 2016):

i) human-generated (e.g., notes, email, and paper documents);

ii) machine-generated monitoring;

iii) financial transactions;

iv) biometric data (e.g., genomics, genetics, x-ray, and electrocardiogram, ECG);

v) social media; and

vi) publications.

Van den Broek, E.L. (2017). ICT: Health's best friend and worst enemy? In E.L. van den Broek, A. Fred, H. Gamboa, and M. Vaz (Eds.), BioSTEC 2017: 10th International Joint Conference on Biomedical Engineering Systems and Technologies, Proceedings Volume 5: HealthInf, p. 611-616. February 21-23, Porto, Portugal. 
A range of apps already exist that conduct limited next-generation medical check-ups, using such data. However, often they are not clinically validated. Examples include e-coaches that support you with sleeping (Beun, 2013), running, and eating to reduce diabetics (Georga et al., 2014). However, many of these apps use no or only basic biometric sensors (cf. (van den Broek, 2010)). So, there is a world to win for unobtrusive and wearable technologies, when shown to result in reliable signal acquisition and, subsequent, analysis.

In October 2016, the American Medical Association (AMA) shared a view point on health care cost reduction: "Chronic diseases account for 7 of 10 deaths in the United States, and treatment of these diseases accounts for more than $85 \%$ of US health costs, including those incurring exceptional treatment costs. About half of health expenditures in the United States are accounted for by $5 \%$ of patients, yet many chronic conditions are preventable. ... Perhaps the most powerful chronic disease prevention approaches are those that can motivate and facilitate health-promoting choices in daily life."(Dietz et al., 2016). I propose to adopt Mandl and Kohane (2016)'s patient-control, where patients themselves can be asked to collect data. They selected eight reasons for pursuing patient-controlled data:

i) complete data: A more holistic view of patients;

ii) data sharing for coordinated care: Patients as vehicle for data sharing;

iii) as foundation for next-generation medical checkup apps;

iv) support of diagnostic journals (e.g., specific with genetic disorders);

v) data donation for research purposes;

vi) patients as reporters;

vii) an additional pairs of eyes; and

viii) social networking.

I would like to stress the importance of including not-yet-patients, as also healthy people may become patients and, consequently, their contributions are at least as valuable.

Ten years ago, Cary L. Cooper stated: "We're talking now I think about the 21 st century black plague. I see stress as the main source of disease or the trigger for disease in the 21st century developed world." (Newby, ABC Catalyst, 2007). In their handbook, Lundberg and Cooper (2011) provided a rich source of evidence for this strong statement. A few months ago, the European Occupational Safety and Health Agency (EU-OSHA) suggested a possible solution: "Software exists that allows the emotions of a computer user to be monitored remotely - this could even be promoted by the developers as a way of detecting early signs of stress in employees, ...". This would aid all three reasons as it could be part of a next-generation medical check-ups, should realize a significant health care cost reduction, and focusses on stress. The development of such software is considered to be part of health informatics' subfield affective computing. Affective computing can be defined as "the scientific understanding and computation of the mechanisms underlying affect and their embodiment in machines" (p. 10) (van den Broek, 2011). Despite its unquestioned potential, affective computing's inherent interdisciplinary complexity limits its progress in performance, as I already denoted in a series of articles presented at this conference (van den Broek et al., 2009; van den Broek et al., 2010a; van den Broek et al., 2010b; van den Broek et al., 2010c; van den Broek et al., 2011). More specifically, affective computing's complexity primarily lays in:

i) its need for a holistic approach (note. this is not a new idea at all; cf. (Follmer, 2016; Schmitz and Wolkenhauer, 2016);

ii) the fragile theoretical frameworks from medicine (e.g., incl. physiology and neuroscience) and psychology it has to rely on (e.g., (Kalisch et al., 2015; Jarvis, 2016); and

iii) the incredible, continuous variance that characterizes our world (Follmer, 2016; Schmitz and Wolkenhauer, 2016).

Moreover, ICT solutions such as affective computing both has their positive as well as its negative sides, as we will discuss in the next section.

\section{ICT: HEALTH'S BEST FRIEND AND WORST ENEMY?}

Even before the age of smartphones and tablets, Joan Stigliani (1995) identified six main health problems, related to computer usage. Since then, more than two decades elapsed in which ICT usage intensified, nowadays using tablets, smartphones, smartwatches, and hardly desktop PCs anymore. Consequently, starting with Stigliani (1995)'s original list, I composed a new list of the 10 main ICT-related health problems:

i) stress disorders (e.g., burn out) (Åborg and Billing, 2003);

ii) musculoskeletal problems (Åborg and Billing, 2003; Gowrisankaran and Sheedy, 2015), includ-

Van den Broek, E.L. (2017). ICT: Health's best friend and worst enemy? In E.L. van den Broek, A. Fred, H. Gamboa, and M. Vaz (Eds.), BioSTEC 2017: 10th International Joint Conference on Biomedical Engineering Systems and Technologies, Proceedings Volume 5: HealthInf, p. 611-616. February 21-23, Porto, Portugal. 
ing Repetitive Stress Injury (RSI) ${ }^{1}$;

iii) vision problems (Salibello and Nilsen, 1995; Gowrisankaran and Sheedy, 2015);

iv) headache (Salibello and Nilsen, 1995; Gowrisankaran and Sheedy, 2015);

v) obesity (de Jong et al., 2013; Schmiege et al., 2016);

which can be complemented by:

vi) metabolic issues, such as vitamin deficiencies (Palacios and Gonzalez, 2014) and diabetics (de Jong et al., 2013);

vii) addiction (e.g., to games, social media, and Internet (Zhou et al., 2017);

viii) sleeping problems (Beun, 2013; Nuutinen et al., 2014);

ix) social isolation (Cacioppo and Hawkley, 2003; Liu and Baumeister, 2016); and

$\mathrm{x}$ ) an unrealistic world view (e.g., resulting in depression) (Donnelly and Kuss, 2016; Wood et al., 2016)

Note that, compared to Stigliani (1995)'s original list, this list includes both more indirect ICT-related and more mental health problems.

If any ICT branch should be health's best friend, it is health informatics. In solving its challenges, health informatics relies on both clinical experience and knowledge of public health systems and organizations, while conducting experiments, interventions, and scalable approaches. (Kulikowski et al., 2012). Par excellence, ICT's health informatics, should contain the identified computer-related health problems. From an ethical point of view, the ICT community should even consider this as one of its main priorities.

When going through scientific literature, health informatics seems to have solved all ICT-related health problems. For example, musculoskeletal problems can be prevented using persuasive technology (Wang et al., 2014), the problem of obesity is approached similarly (Wang et al., 2014), as are headache (Minen et al., 2016), diabetics (Georga et al., 2014), sleeping problems (Beun, 2013), and social isolation (Chen and Schulz, 2016). So, it seems to be a case of "One size fits all" (Suomi, 1996). However, many solutions are fragile, random control trails are absent or conducted at a small scale, and solutions are at a gadget level, instead of at the level

\footnotetext{
${ }^{1}$ Note. Stigliani (1995) mentioned RSI as separate entry. However, essentially it is a musculoskeletal problem and, hence, placed here under this entry.
}

of aimed clinical solutions. Many roads can be followed to remedy this practice. The problem lies is the increasing tendency to just see what the computer shows. (van den Broek, 2012)

In the next section, I will pose one critical concept for health informatics, complementary to the prerequisites defined before (van den Broek et al., 2009; van den Broek et al., 2010a; van den Broek et al., 2010b; van den Broek et al., 2010c; van den Broek et al., 2011): personality. Par excellence, this concept illustrates affective computing's threefolded complexity, as depicted in Section 1. Moreover, health informatics is also the claimed road towards next-generation personalized medicine (Poon et al., 2013). How can this be, if clients personalities are ignored?

\section{PERSONALITY}

The urge to completely redesign our health care system relies on a both crucial and often ignored determinant: personality. For each of the three reasons for this call for a paradigm shift, I will explain why personality is an essential part of the equation:

i) Next-generation medical check-ups are personalized. However, solely the medical check-up does not help; in particular, healthy people have to be persuaded to start, improve, or maintain a healthy living style. Tailored health messages are needed, next-generation customized (semi)automatic ICT-based communication (Kreuter et al., 2012).

ii) I proposed to implement Mandl and Kohane (2016)'s patient-control paradigm and extend it to people-health control to realize cost reduction; that is, ask people themselves to collect their data. This requires sincere cooperation from people, as they are asked to contribute to their own electronic health records.

iii) The $21 \mathrm{st}$ century black plague is directly linked to people's coping style and, hence, personality (Zhou et al., 2017). "Coping is often defined as efforts to prevent or diminish threat, harm, and loss, or to reduce associated distress. Some prefer to limit the concept of coping to voluntary responses; others include automatic and involuntary responses within the coping construct. ...Personality does influence coping in many ways, however, some of which occur prior to coping. Even prior to coping, personality influences the frequency of exposure to stressors, the type of stressors experienced, and appraisals" (Carver

Van den Broek, E.L. (2017). ICT: Health's best friend and worst enemy? In E.L. van den Broek, A. Fred, H. Gamboa, and M. Vaz (Eds.), BioSTEC 2017: 10th International Joint Conference on Biomedical Engineering Systems and Technologies, Proceedings Volume 5: HealthInf, p. 611-616. February 21-23, Porto, Portugal. 
and Connor-Smith, 2010).

With a foundation provided for personality's key role in the proposed paradigm shift, I will now sketch its history, challenges as well as a solution approach.

In this article, at a functional level, I will take a methodological perspective to personality and describe it in terms of its research traditions (or approaches) (Pervin, 2003):

i) clinical (e.g., including Freud's work);

ii) statistical (e.g., the big-five (BF) model); and

iii) experimental (e.g., including the work of Wundt, Pavlov, and Skinner).

Clinical approaches to personality allow a holistic approach, while observing a great variety of phenomena, using self-reports and behavioral observations. As such they satisfy two of the three dimensions of complexity (i.e., holistic approach and explain the huge variance). However, clinical approaches to personality fail in the third dimension of complexity: generation of solid theoretical frameworks, as reliable observations and tests of hypotheses are complicated if possible at all. Statistical approaches to personality focus on individual differences, using trait questionnaires instead of self-reports. This practice enables statistical analysis of the relation between personality traits and other variables. However, this approach suffers from studies on non-representative samples (e.g., students) and a lack of both generalizability and specificity. The statistical approach can provide theoretical frameworks; but, fails to take a true holistic approach and simplifies reality and, hence, is unable to explain the existing real world variance in personality traits. Experimental approaches to personality rely on laboratory studies on cause-effect relationships, as such they are the opposite of clinical approaches. They violate the holistic approach and cannot explain the huge variance of the real world. However, they comply to the third dimension of complexity: generation of solid theoretical frameworks.

Models and theory used in affective computing are heavily skewed towards the statistical approaches (cf. (Vinciarelli and Mohammadi, 2014)). To some extent this makes sense as the statistical approaches are most straightforward to model (e.g., using machine learning or general linear models). Although understandable from a pragmatic stance, the above analysis of the three research traditions of personality makes it hard to justify this position. I propose to reconsider and improve the clinical approach to personality, such that computational models can be build based on it. This requires a well-argued combination of lab and field data and, most likely, a merge of quantitative and qualitative data (Fine and Elsbach, 2000;
McCusker and Gunaydin, 2015).

\section{CONCLUSION}

Health care is vibrant and yet conservative, a highly complex field of science, engineering, and practice. As is argued in Section 1, its foundations should be reconsidered. ICT, and in particular, health informatics, can play a crucial role in this process. However, the stakes are high, including potentially big losses as well as big gains, as is discussed in Section 2, which makes such endeavor even more challenging. With paradigms such as personalized medicine and mobile health, the client is put central. However, so far the client's personality has been ignored (see Section 3). I pose that the clinical tradition of personality research should be embraced by health informatics, realizing that this would require a firm step back to enable the so much needed steps forward.

As is illustrated via this article's relatively lengthly list of references, an interdisciplinary, holistic approach was taken. Nevertheless, many issues remained untouched. For example, social and cultural (Kaplan, 2017) and psychosocial issues (Kun, 2016) should be considered on top of the evident privacy and security concerns (Blobel et al., 2016). An analysis of the current state-of-the-art of electronic health records would have been appropriate as well (Wuyts et al., 2012; Stylianou and Talias, 2017). Moreover, a discussion on computational techniques for personality models at a functional level would have been in place (cf. (Huys et al., 2016; Adams et al., 2016)). However, this article's list of references provides a good starting point.

Health informatics is struggling, already since its recent conception (Kulikowski et al., 2012; Nelson and Staggers, 2018). Omnipresent computing power, big data, rapidly improving sensor technology, and our extended lives, have put it in the top list of society's health agenda. This is a promising trend; but, as posed, significantly more mass is needed to change the field's paradigm and see all humans as clients, instead of only those who are already patients.

\section{ACKNOWLEDGMENTS}

I thank the two anonymous reviewers, who provided excellent comments on an early draft of this article. Moreover, I thank Winnie Teunissen for carefully proof reading of the pre-final version of this article. Last, I thank Gert-Jan de Vries for his invitation to present this article at his special session.

Van den Broek, E.L. (2017). ICT: Health's best friend and worst enemy? In E.L. van den Broek, A. Fred, H. Gamboa, and M. Vaz (Eds.), BioSTEC 2017: 10th International Joint Conference on Biomedical Engineering Systems and Technologies, Proceedings Volume 5: HealthInf, p. 611-616. February 21-23, Porto, Portugal. 


\section{REFERENCES}

Åborg, C. and Billing, A. (2003). Health effects of 'the paperless office' - evaluations of the introduction of electronic document handling systems. Behaviour \& Information Technology, 22(6):389-396.

Adams, R. A., Huys, Q. J. M., and Roiser, J. P. (2016). Computational psychiatry: towards a mathematically informed understanding of mental illness. Journal of Neurology, Neurosurgery \& Psychiatry, 87(1):53-63.

Bartol, T. (2016). Recreating healthcare: The next generation. The Nurse Practitioner, 41(11):10-11.

Beun, R. J. (2013). Persuasive strategies in mobile insomnia therapy: alignment, adaptation, and motivational support. Personal and Ubiquitous Computing, 17(6):1187-1195.

Blobel, B., Lopez, D. M., and Gonzalez, C. (2016). Patient privacy and security concerns on big data for personalized medicine. Health and Technology, 6(1):75-81.

Cacioppo, J. T. and Hawkley, L. C. (2003). Social isolation and health, with an emphasis on underlying mechanisms. Perspectives in Biology and Medicine, 46(3 Supplement):S39-S52.

Carver, C. S. and Connor-Smith, J. (2010). Personality and coping. Annual Review of Psychology, 61:679-704.

Chen, Y.-R. R. and Schulz, P. J. (2016). The effect of information communication technology interventions on reducing social isolation in the elderly: A systematic review. Journal of Medical Internet Research, 18(1):e18.

de Jong, E., Visscher, T. L. S., HiraSing, R. A., Heymans, M. W., Seidell, J. C., and Renders, C. M. (2013). Association between TV viewing, computer use and overweight, determinants and competing activities of screen time in 4- to 13-year-old children. International Journal of Obesity, 37(1):47-53.

Dietz, W. H., Douglas, C. E., and Brownson, R. C. (2016). Chronic disease prevention: Tobacco avoidance, physical activity, and nutrition for a healthy start. Journal of the American Medical Association (JAMA), 316(16):1645-1646.

Donnelly, E. and Kuss, D. J. (2016). Depression among users of social networking sites (SNSs): The role of SNS addiction and increased usage. Journal of Addiction and Preventive Medicine, 1(2):\#107.

Fang, R., Pouyanfar, S., Yang, Y., Chen, S.-C., and Iyengar, S. S. (2016). Computational health informatics in the big data age: A survey. ACM Computing Surveys (CSUR), 49(1):Article No. 12

Ferlie, E., Montgomery, K., and Pedersen, A. R. (2016). The Oxford Handbook of health care management. Oxford, UK: Oxford University Press, 1st edition.

Fine, G. A. and Elsbach, K. D. (2000). Ethnography and experiment in social psychological theory building: Tactics for integrating qualitative field data with quantitative lab data. Journal of Experimental Social Psychology, 36(1):51-76.
Follmer, E. (2016). What we do to fit in: personality, coping, and Person-Environment fit. $\mathrm{PhD}$ thesis, Graduate College, The University of Iowa, Iowa City, IA, USA.

Georga, E. I., Protopappas, V. C., Bellos, C. V., and Fotiadis, D. I. (2014). Wearable systems and mobile applications for diabetes disease management. Health and Technology, 4(2):101-112.

Gowrisankaran, S. and Sheedy, J. E. (2015). Computer Vision Syndrome: A review. Work, 52(2):303-314.

Huys, Q. J. M., Maia, T. V., and Frank, M. J. (2016). Computational psychiatry as a bridge from neuroscience to clinical applications. Nature Neuroscience, 19(3):404-413.

Jarvis, C. (2016). Physical examination and health assessment. St. Louis, MO, USA: Elsevier, Inc., 7th edition.

Kalisch, R., Müller, M. B., and Tüscher, O. (2015). A conceptual framework for the neurobiological study of resilience. Behavioral and Brain Sciences, 38:e92.

Kaplan, J. (2017). Artificial Intelligence: Think again. Communications of the ACM, 60(1):36-38.

Kreuter, M., Farrell, D., Olevitch, L., and Brennan, L. (2000/2012). Tailoring health messages: Customizing communication with computer technology. LEA's Communication Series. Mahwah, NJ, USA: Routledge, Taylor \& Francis Group / Lawrence Erlbaum Associates, Inc., reprint edition.

Kulikowski, C. A., Shortliffe, E. H., Currie, L. M., Elkin, P. L., Hunter, L. E., Johnson, T. R., Kalet, I. J., Lenert, L. A., Musen, M. A., Ozbolt, J. G., Smith, J. W., Tarczy-Hornoch, P. Z., and Williamson, J. J. (2012). AMIA Board white paper: definition of biomedical informatics and specification of core competencies for graduate education in the discipline. Journal of the American Medical Informatics Association, 19(6):931-938.

Kun, L. (2016). Introductory remarks to the special issue on social implications of technology, in honor of the late dr. Lodewijk Bos. Health and Technology, 6(1):1-4.

Liu, D. and Baumeister, R. F. (2016). Social networking online and personality of self-worth: A meta-analysis. Journal of Research in Personality, 64:79-89.

Lundberg, U. and Cooper, C. L. (2011). The science of occupational health: Stress, psychobiology, and the new world of work. Chichester, West Sussex, UK: Wiley-Blackwell / John Wiley \& Sons Ltd.

Mandl, K. D. and Kohane, I. S. (2016). Time for a patientdriven health information economy? The New England Journal of Medicine, 374(3):205-208.

McCusker, K. and Gunaydin, S. (2015). Research using qualitative, quantitative or mixed methods and choice based on the research. Perfusion, 30(7):537-542.

Minen, M. T., Torous, J., Raynowska, J., Piazza, A., Grudzen, C., Powers, S., Lipton, R., and Sevick, M. A. (2016). Electronic behavioral interventions for headache: A systematic review. The Journal of Headache and Pain, 17(1):Article 51.

Van den Broek, E.L. (2017). ICT: Health's best friend and worst enemy? In E.L. van den Broek, A. Fred, H. Gamboa, and M. Vaz (Eds.), BioSTEC 2017: 10th International Joint Conference on Biomedical Engineering Systems and Technologies, Proceedings Volume 5: HealthInf, p. 611-616. February 21-23, Porto, Portugal. 
Nelson, R. and Staggers, N. (2018). Health informatics: An interprofessional approach. St. Louis, MO, USA: Elsevier, Inc., 2nd edition.

Newby, ABC Catalyst, J. (06/09/2007). Workplace stress: Stopping the juggernaut. URL: http://www.abc . net.au/catalyst/stories/s2025212.htm [Last accessed on January 5, 2017].

Nuutinen, T., Roos, E., Ray, C., Villberg, J., Välimaa, R., Rasmussen, M., Holstein, B., Godeau, E., Beck, F., Léger, D., and Tynjälä, J. (2014). Computer use, sleep duration and health symptoms: A crosssectional study of 15 -year olds in three countries. International Journal of Public Health, 59(4):619-628.

Palacios, C. and Gonzalez, L. (2014). Is vitamin D deficiency a major global public health problem? The Journal of Steroid Biochemistry and Molecular Biology, 144(Part A):138-145.

Pervin, L. A. (2003). The Science of Personality. New York, NY, USA: Oxford University Press, Inc., 2nd edition.

Poon, C. C. Y., Wang, M. D., and Bonato, P. (2013). Editorial: Special issue on health informatics and personalized medicine. IEEE Transactions on Biomedical Engineering, 60(1):143-146.

Salibello, C. and Nilsen, E. (1995). Is there a typical VDT patient? a demographic analysis. Journal of the American Optometric Association, 66(8):479-483.

Schmiege, S. J., Gance-Cleveland, B., Gilbert, L., Aldrich, H., Gilbert, K. C., and Barton, A. (2016). Identifying patterns of obesity risk behavior to improve pediatric primary care. Journal of Specialists in Pediatric Nursing, 21(1):18-28.

Schmitz, U. and Wolkenhauer, O. (2016). Systems Medicine, volume 1386 of Methods in Molecular Biology / Springer Protocols. New York, NY, USA: Humana Press / Springer Science+Business Media.

Stigliani, J. (1995). The computer user's survival guide: Staying healthy in a high tech world. Sebastopol, CA, USA: O'Reilly Associates, Inc.

Stylianou, A. and Talias, M. A. (2017). Big data in healthcare: A discussion on the big challenges. Health and Technology, 7:[in press].

Suomi, R. (1996). One size fits all - or does it? Behaviour \& Information Technology, 15(5):301-312.

van den Broek, E. L. (2010). Beyond biometrics. Procedia Computer Science, 1(1):2505-2513.

van den Broek, E. L. (2011). Affective Signal Processing (ASP): Unraveling the mystery of emotions. PhD thesis, Human Media Interaction (HMI), Faculty of Electrical Engineering, Mathematics, and Computer Science, University of Twente, Enschede, The Netherlands.

van den Broek, E. L. (2012). Affective computing: A reverence for a century of research, volume 7403 of Lecture Notes in Computer Science, pages 434-448. Berlin/Heidelberg, Germany: Springer-Verlag. van den Broek, E. L., Janssen, J. H., Healey, J. A., and van der Zwaag, M. D. (2010a). Prerequisites for Affective Signal Processing (ASP) - Part II. In Fred, A. Filipe, J., and Gamboa, H., editors, Biosignals 2010: Proceedings of the International Conference on BioInspired Systems and Signal Processing, pages 188193, Valencia - Spain.

van den Broek, E. L., Janssen, J. H., van der Zwaag, M. D., and Healey, J. A. (2010b). Prerequisites for Affective Signal Processing (ASP) - Part III. In Fred, A., Filipe, J., and Gamboa, H., editors, Biosignals 2010: Proceedings of the International Conference on BioInspired Systems and Signal Processing, pages 432 435, Valencia - Spain.

van den Broek, E. L., Janssen, J. H., van der Zwaag, M. D., Westerink, J. H. D. M., and Healey, J. A. (2011). Prerequisites for Affective Signal Processing (ASP) Part V: A response to comments and suggestions. In Proceedings of the International Conference on BioInspired Systems and Signal Processing, pages 301306, Rome, Italy.

van den Broek, E. L., Janssen, J. H., Westerink, J. H. D. M., and Healey, J. A. (2009). Prerequisites for Affective Signal Processing (ASP). In Encarnação, P. and Veloso, A., editors, Biosignals 2009: Proceedings of the International Conference on Bio-Inspired Systems and Signal Processing, pages 426-433, Porto - Portugal.

van den Broek, E. L., van der Zwaag, M. D., Healey, J. A., Janssen, J. H., and Westerink, J. H. D. M. (2010c). Prerequisites for Affective Signal Processing (ASP) Part IV. In Kim, J. and Karjalainen, P., editors, Proceedings of the 1st International Workshop on Bioinspired Human-Machine Interfaces and Healthcare Applications - B-Interface, pages 59-66, Valencia Spain.

Vinciarelli, A. and Mohammadi, G. (2014). A survey of personality computing. IEEE Transactions on Affective Computing, 5(3):273-291.

Wang, S.-C., Jiang, C., and Chern, J.-Y. (2014). Promoting healthy computer use: Timing-informed computer health animations for prolonged sitting computer users. Behaviour \& Information Technology, 33(3):295-301.

Wood, M. A., Bukowski, W. M., and Lis, E. (2016). The digital self: How social media serves as a setting that shapes youths emotional experiences. Adolescent Research Review, 1(2):163-173.

Wuyts, K., G, V., Scandariato, R., Joosen, W., and Dumortier, J. (2012). What electronic health records dont know just yet. a privacy analysis for patient communities and health records interaction. Health and Technology, 2(3):159-183.

Zhou, Y., Li, D., Li, X., Wang, Y., and Zhao, L. (2017). Big five personality and adolescent internet addiction: The mediating role of coping style. Addictive Behaviors, 64:42-48.

Van den Broek, E.L. (2017). ICT: Health's best friend and worst enemy? In E.L. van den Broek, A. Fred, H. Gamboa, and M. Vaz (Eds.), BioSTEC 2017: 10th International Joint Conference on Biomedical Engineering Systems and Technologies, Proceedings Volume 5: HealthInf, p. 611-616. February 21-23, Porto, Portugal. 